\title{
Impact of Mobile Phone in Life Style of Gaddi Tribes
}

\author{
Ravi Raj ${ }^{1 *}$, Rajesh Kumar' ${ }^{2}$, Vipin Kumar ${ }^{3}$ \\ ${ }^{1}$ Principal, Namdhari College of Education, Sunder Nagar, India \\ ${ }^{2,3}$ Assistant Professor, Namdhari College of Education, Sunder Nagar, India \\ *Corresponding author: rrsareli@gmail.com
}

\begin{abstract}
The strong correlation between education and democracy has been widely accepted and explored in many ways. This study is inspired by the quest for the democratization of school education through the lenses of social science learning at the secondary education level in the Indian context. The study tried to visualize to what extent schooling contributes to the making of democratic beings. Education for democratic citizenship is directed by various factors such as school education policies, curriculum frameworks, curricular and co-curricular activities or indirectly by attitudes and practices through which democratic knowledge, skills, values and attitudes is constructed to create a future democratic citizen. Thus, to give light to this area, a qualitative study has been designed to look at the selected components of education for democratic citizenship in school settings. The Research investigated social science teachers and student's views on democracy and its practices to examine how close these schools were to become 'democratic schools'. Results showed that teaching of teaching for democracy is not as it is presented in literature and educational document. This study is meant to grab a severe concern towards current conceptualization and school practices related to democracy, to create active and democratic citizens in thoughts and practices both, by taking simple steps at the school level to bring significant differences to create a democratic society.
\end{abstract}

Keywords: Communication, Status, Social-barriers, Social-life.

\section{Introduction}

The Mobile phones (Cuervo et al., 2010; Enck et al., 2014) are an essential part of human life and a new technological invention of human beings to this world. The Mobile phones are enhanced with variety of different sophisticated features which allow users to store photos, memories, personal information, communications, health and financial data in one place. Some Mobile Phones are also an integral part of modern telecommunication facilities. In some parts of the world, they are the most reliable or only available phones. These phones allow people to maintain continuous communication without interrupting their movement or distance. Mobile phones and handheld devices (HHD) combine advanced computing capabilities, such as internet communication, information retrieval, video, e-commerce and other features to make the device a must for many people. "Mass mobile mobilization" may have covered people 10 to 15 years ago. According to GSMA Intelligence, the number of mobile devices is 7.22 billion and the US Census Bureau says that number is still between 7.19 million and 7.2 billion. The growing number of its users are concerned about the impact mobile phones have on human health and life.

The worldwide popularity of mobile phones and a little understanding of their side effects prompted the author to understand the impact of mobile phones on human health and life. The Merriam-Webster dictionary defines mobile phones as "cell phone with additional software features (such as e-mail and internet browser). In this study, the author suggests that mobile phones to handheld devices.

\section{A. The impact of the mobile phone on young people's social life}

The adoption of mobile phones (Mohan et al., 2008) by young people has become a global phenomenon. It is an integral part of the daily life of adolescents now and is the most popular form of electronic communication. In fact, mobile phones (Mohan et al., 2008) have changed from technical tools to social tools. Young people are actively using mobile phones (Mohan et al., 2008) to organize and maintain social networks. However, the fellowship of young people also has an adverse effect. These may include exclusions and cyber bullying. Similarly, mobile phones (Mohan et al., 2008) have changed the dynamics of families, and from the perspective of parents, security and surveillance issues have brought about changes in youth freedom through negotiations. While function coordination is beneficial to families, but it can also other problems such as financial difficulties, access to non-custodial parent access, addressing security issues and excessive reliance on the mobile phone for safety issue and instruction into young people lives. However, the impact of mobile phones (Mohan et al., 2008) as a school as an educational institution has not been studied as much as possible. Course interference, cheating and bullying are some of the negative effects, and swearing parents seem to be the only positive factor in this school. Further research is needed on the consequences of using mobile phones (Mohan et al., 2008) at schools.

The invention of landlines in the late 19th century changed the way people interact and communicate. This had been advent of mobile phones; this was similar to the early 21 st century. 
This phone was originally designed for business users (Aoki \& Downes, 2003). This is very similar to landlines in the early 20th century. Telephone engineers explained that are not suitable for social conversations in the business world. The growth of mobile phone technology is reflected in the fact that the number of mobile phone users worldwide has exceeded the number of fixed-line users in 2002 (Srivastava, 2005). The number of mobile phone users is expected to increase by the end of 2005 with 2 billion mobile phone users worldwide and Australia reaching 19.20 million (Fisher, 2005).

Young people have not only mobile phones but also "symbolic and emotional investments" (Lobet-Maris, 2003, p. 88). It has been consistently shown that young people prefer cell phones, televisions and the Internet. This is the best way for children to communicate (Livingstone \& Bober, 2005). Teenagers (10 to 12 years of grade) have reported that if they forget the phone they need to return to their home and receive a phone call (Matthews, 2004). Young people also save text messages which they value and cherish (Taylor \& Harper, 2003).

The mobile phones are status symbols for young people. The feature of mobile phones, appearance, and personalized accessories all prove mobile phone status, with $60 \%$ of teenagers reporting enthusiastic mobile upgrades. It is considered as a fashion accessory that meets individual needs by selected mobile wallpapers, ringtones, phone cases, handbags and other accessories (Srivastava, 2005), but it also means that it is part of the same industry. The ownership of mobile phones indicates that people are socially accessible and in trouble. It can also be regarded as a symbol of independence from one family.

\section{B. The impact of the mobile phone on the peer group}

The mobile phones have a broad impact on young people group has been extensive. Adolescence is the time of change and influence of peer groups (Ling \& Helmersen, 2000), and communication among members of peer groups is at the center of an individual identity. The impact of mobile phones on peer relationships has transformed the peer group into a truly online network society.

\section{1) Functional}

One of the main reasons young people use mobile phones is the "micro-coordination" of their social life. Adolescents can adjust or reorganize social functions very quickly, resulting in a "more fluid and interactive social interaction culture" (Geser, 2004 , p. 20). This communication feature is further enhanced by using unavailable mobile phones. It cannot be adjusted, but it cannot leave space, that is, it must remain in a specific place (Geser, 2004). The power of the ability of mobile phones makes young people more flexible and spontaneous in their lives. Young people can adjust or reorganize social functions very quickly, leading to a "more fluent interactive culture of the information society" (Geser, 2004, p. 20). For example, mobile phones are used to allow hundreds of young people to attend parties (Weston, Atkinson, \& Giles, 2005).

\section{2) Relational}

However, the most important impact of mobile phones is the connection between young people and their peer groups. Even the use of the telephone is intertwined with the use of the connection; that is, there is no adult interference, so the companion can be closer than the landline. In a New Zealand study, $56 \%$ of high school students said that the most important reason for using mobile phones is to talk text messages with friends. This relationship is important, as the rules of participation indicate. One of the new rules is that you expect to respond to text messages in 15 to 30 minutes and if send later must be accompanied by an apology (Kasesniemi \& Rautiainen 2002).

\section{3) Negative}

However, with these positive effects, there is also the downside of using a cell phone for young people. This includes emotions hiding behind technology, such as closing relationships, eliminating people without mobile phones, and cyber bullying. Some sociologists believe that many young people choose sentences rather than talking about puzzles and emotional difficulties (Srivastava, 2005). Fox (2001) concluded with a focus group interview, text messaging is a very convenient way to stay in touch without spending time and effort. It allows shy and conservative young people to communicate without feeling embarrassed, while encouraging even their ability to write even cheeky text. Due to character limitations, text messages are basically limited and requires a brief, without social details.

In relationship to be a contradiction in this study young people who do not have cell phones supposed to be in contradictions in this study. In the UK, researchers have point out that non-mobile owners are particularly vulnerable to social exclusion (Charlton, Panting, \& Hannan, 2002). According to a survey in Australia, nearly half of young people who do not have mobile phones feel that they are not involved in social activities, and that one third is being pressured by friends to get one $(91 \%)$ of teenagers with mobile phones report that they respect young people who don't think mobile phones are necessary. Perhaps this suggests that teenagers will not consider do not excluding non-mobile users, but may say that they may be excluded because they cannot be excluded because they cannot be contacted easily. However, it is also possible respondents can also answer this question in a socially desirable manner.

Another negative factor in the use of mobile phones is the young bullying others. It seems to be some studies, this phenomenon has been found and studied as the text message of most internet bullying victims (Campbell \& Gardner, 2005). Face the consequences of bullying, depression, anxiety, psychosomatic symptoms and even suicide increase (Rantanen, \& Rimpela, 2000; Neary \& Joseph, 1994). In addition, research on the effects of Internet bullying may be more serious than faces facing bullying. When bullying rants, the victim remembers every word, but through text messaging, it may not 
be possible to target and student can read this message. It sounds more specific than words, "Ring real." 24/7 aspects of net bullying allowed at any time of day and night are on the mobile phone, there is no escape.

\section{Research Design}

\section{A. Exploratory and Descriptive in Nature}

When a researcher has an idea or has observed something and seeks to understand more about it normally adopts exploratory design. An exploratory research project is an attempt to lay the groundwork that will lead to future studies or to determine if what is being observed might be explained by a currently existing theory. Most often, exploratory research lays the initial groundwork for future research. Explanatory research looks at how things come together and interact. Researcher being in initial stage used this for gaining more insight about the topic.

Exploratory research is followed by descriptive research. When the newly explored field needs more information descriptive design is widely used. Descriptive research is defined as defined as attempts to explore and explain while providing additional information about a topic. In descriptive research is trying to describe what is happening in more detail, filling in the missing parts and expanding our understanding. This is also where as much information is collected as possible.

\section{B. Mixed Method}

Mixed Method is adopted in this study as it is considered as stronger than other method. The research objective requires both Quantitative and Qualitative data. Interpreting both quantitative and qualitative data for analysis is possible by using mixed method. This method is widely adopted by the social scientists in impact study. The nature of the study has paved way for the researcher to use mixed mode which is widely accepted by the social scientists globally.

\section{Data Collection Method}

Primary Data will be collected using well designed schedule in the area of the study. Schedule will be adopted mainly because the some of the respondents using mobile may be illiterate and moreover researcher will himself collect the data directly with schedule will give more idea to the researcher while collecting data in field. This will help us to estimate the usage of mobile phone, its penetration, and pattern of uses, spending of community on mobile recharges, frequency of spending, whether spending on talk time or on data pack. This will help the researcher. More interesting facts may be visible during data collection which will enhance the quality, and provide new dimension to the research.

\section{Sample Size}

300 Mobile Phone users of Gaddi Tribes from different blocks of Chamba District of Himachal Pradesh will be collected Respondents will be irrespective of age, gender, educational, Qualification, income, area of residence.

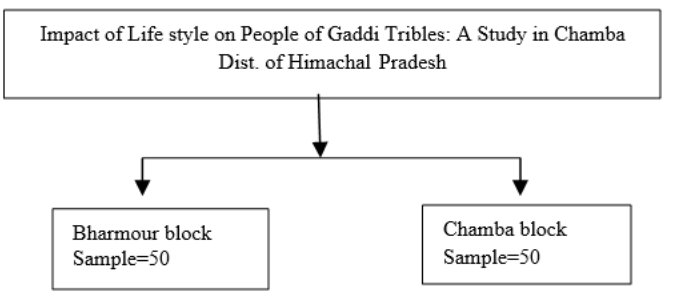

Fig. 1. Impact of life style

\section{E. Sample Technique}

Convenience sampling techniques will be adopted. Convenience sampling is a type of sampling where the first available primary data source will be used for the research. The only requirement is the respondent must be using a mobile phone. In other words, this sampling method involves getting participants wherever you can find them and typically wherever is convenient. In convenience sampling all subjects are invited to participate if they use mobile phone facilities, irrespective of type of mobiles.

\section{F. Statistical Tool}

As study is based on exploratory and descriptive type following tools will be used.

Simple Percentage: This will help us to analyze the data with more clarity which can be easily understood by the readers. This will help us to represent the complex data collected in a much simpler manner.

\section{Literature Review}

Vandana Goswami et al. (2016) the effects of mobile phones are affecting the lives of young people. According to him, the use of mobile phones is a strong act like youth because they have to stop their daily activities. The main purpose of this article is to prove that certain aspects of the emerging literature should investigate the lives of teenagers with mobile phones.

M. J. Cilliers et al. the study on the social impact of mobile phones has not been exposed to other mobile devices, and research on the social impact of mobile phones on young people has changed the mobile infrastructure in the last decade.

Rhea John (2013) Studied was report on Krishnaraj and read in summer travel report. This article attempts to understand how games records the impact on life and discusses their progress. According to their day-to-day strategy, their economy Gaddi ultimately faces the risk of diminishing risk the sustainability of its environment, Shepherd experience Royal 1985), or their extensive religious and cultural practices.

Shubham et al. (2017) study of to use cell phones by student for radiation gave a great impression on the human mind. Distance between the phone and the human body: When the phone is one inch from the human body, the radiation can be reduced significantly. The power of the signal decreases with the distance from the signal source. This means that as in our head phones, when they double the distance from the sound source, there is four quarters so the signal power is reduced to a quarter. 


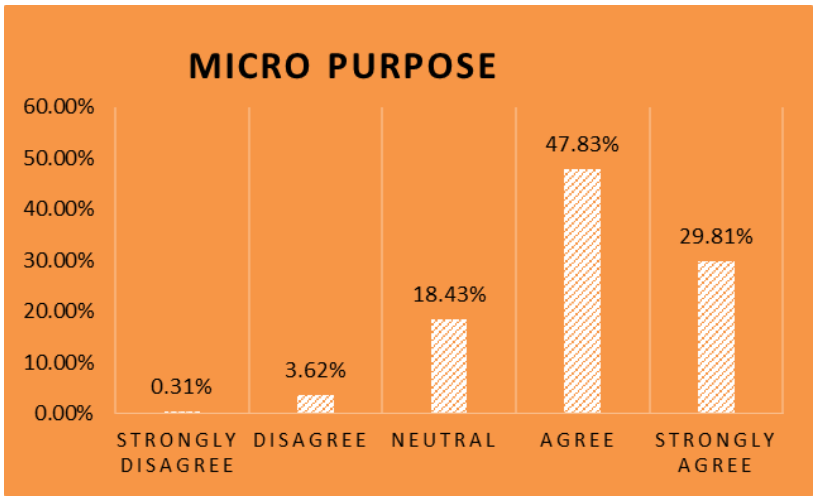

Fig. 2. Micro purpose

As per the fig. 2, 77\% person agreed that they accepted Micro phone is good for Micro purpose for Gaddi community 19\% filling neutral and 3\% person not feeling good. Hence we can conclude that the most of the person agreed mobile is useful for micro purpose.

\section{Age Group}

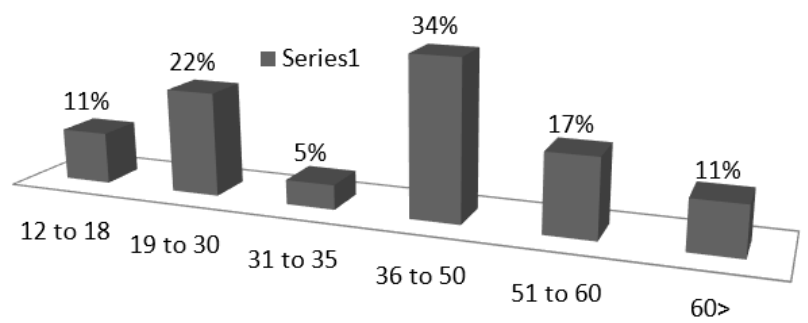

Fig. 3. Age group

As per the fig. 3, participant who include in this survey their age group is like below. 11\% respondent their age group 12-18, $22 \%$ respondent fall under $19-30$ age group, $5 \%$ respondent fall under $31-35,34 \%$ person fall under $36-50$ age $17 \%$ person fall under 51-60 group and $11 \%$ person their age more than 60 years.

\section{Conclusion}

It was seen that increasing adaptability of mobile phones among the gaddi tribes have caused a social barrier among between parents and children. It has been seen as a major factor of shortening of social relations between them. The mobile phones have increased the economic and communication facilities but has hardened the social relations among people.

\section{References}

[1] Barber, B. K., \& Buehler, C. (1996). Family cohesion and enmeshment: Different constructs, different effects. Journal of Marriage and the Family, 433-441.
[2] Basu, and Rajan (1985) Tribal Development Programme and Administration in India, National Book Organization, Green Park Extension, New Delhi.

[3] Bottomore, T.B. (1964) Sociology, Free Press, London.

[4] Brown, Redcliffe (1957), A Natural Science of Society, Free Press, New York.

[5] Castells, M., \& Cardoso, G. (Eds.). (2006). The network society: From knowledge to policy (pp. 3-23). Washington, DC: Johns Hopkins Center for Transatlantic Relations.

[6] Castells, M., Fernandez-Ardevol, M., Qiu, J. L., \& Sey, A. (2009). Mobile communication and society: A global perspective. Mit Press.

[7] Chosen, P.S., (1968), Modern Social Theory, Heinemann, London.

[8] Ghurye, G.S (1963), The caste and class in India: The schedule Tribes, Popular Book Deport, Bombay.

[9] Ginsberg, M. (1947), Reason and Unreason in Society, London.

[10] Government of Himachal Pradesh (2007), Development Block Index, Chamba.

[11] Government of Himachal Pradesh (2007-2008), Econonic Survey Himachal Pradesh, Department of Economics and Statistics, Himachal Pradesh, Shimla.

[12] Government of Himachal Pradesh, Census of India (2001), Directorate of census operation, Himachal Pradesh.

[13] Government of India (1991), Census of India, Ministry of Tribal Affairs, New Delhi.

[14] Government of India (2005), Himachal Pradesh Development Report, Planning Commission, New Delhi.

[15] GSM Association. (2015). The Mobile Economy 2015. URL: http://www. Gsma mobileeconomy. com/GSMA_Global_Mobile_Economy_Report_2015.pdf

[16] James, J. (2010). Penetration and growth rates of mobile phones in developing countries: An analytical classification. Social indicators research, 99(1), 135-145.

[17] Kalia, S.L (1961), "Sanrkritization and Tribalisation" in eds. T.B Naik, Changing Tribes, Tribal Research Institute, Chhindwara.

[18] Levi Strauss Claude (1953), Social Structure in Anthropology Today, Ed. A.L. Kroeber, Chicago.

[19] Luthar, B., \& Kropivnik, S. (2011). Class, Cultural Capital, and the Mobile Phone. Sociologický časopis/Czech Sociological Review, 47(06), 1091-1118.

[20] Maclver, R.M. and Page, C.G (1959), Society; An Introductory analysis, Macmillan and Company, London.

[21] Majumdar, D.N., (1961), Races and Culture of India, Asia Publishing House, Bombay.

[22] Majumdar, D.N., (1966), The Grammar of Sociology, Asia Publishing House, Bombay.

[23] Marg, J. N. (2014). Telecom Regulatory Authority of India.

[24] Mudliar, P., Donner, J., \& Thies, W. (2012, March). Emergent practices around CGNet Swara, voice forum for citizen journalism in rural India. In Proceedings of the Fifth International Conference on Information and Communication Technologies and Development (pp. 159168). ACM.

[25] Negi, T.S. (1976), Scheduled Tribes of Himachal Pradesh, Raj Printer Meerut.

[26] Newell, William H., (1965), Report on the SC \& ST - Himachal Pradesh, Census of India, 1961, Vol. 20, Part V-B, Delhi.

[27] Olson, D. H., Sprenkle, D. H., \& Russell, C. S. (1979). Circumplex model of marital and family systems: I. Cohesion and adaptability dimensions, family types, and clinical applications. Family process, 18(1), 3-28.

[28] Pertierra, R. (2007). Durkheim, mobiles and the sphere of the society. Philippine Sociological Review, 15-36.

[29] Sachidananda (1978), Social Structure, Status and mobility pattern: The case of Tribal Woman, Man in India.

[30] Saha, A. (2012). Cellphones as a Tool for Democracy: The Example of CGNet Swara. Economic \& Political Weekly, 47(15), 23-26.

[31] Verma, V. (1996), Gaddis of Dhauladhar: A Transhumant Tribe of the Himalaya, Indus Publishing Company, New Delhi.

[32] Wajcman, J., Bittman, M., \& Brown, J. E. (2008). Families without borders: Mobile phones, connectedness and work-home divisions. Sociology, 42(4), 635-65. 